\title{
Mice on the move
}

\author{
Animal welfare concerns, reduced flight options and increased costs are pushing researchers to consider shipping \\ frozen sperm and embryos rather than live mice.
}

\section{Charlotte Harrison}

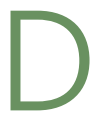

isruption to flight schedules caused by the COVID-19 pandemic didn't just affect human passengers trying to get to different places. The movement of mice, widely used as models of human disease, was also severely restricted.

This constraint was acutely problematic in the early stages of the pandemic as researchers rushed to better understand COVID-19 pathology, and investigate potential treatments and vaccines. At that time, models specific for COVID-19 weren't readily available, so researchers rushed to repurpose existing on-the-shelf options, such as transgenic K18-hACE2 mice; these had been developed to study the earlier SARS outbreak and express the human version of the protein used by SARS-CoV-2 to gain cellular entry. But such mice were only available from a small number of colonies in the United States.

Eric Syversen, who specializes in live animal transport at Validated Delivery Solutions, was tasked with shipping these mice to the labs around the world that urgently needed them. "We were begging airlines to take COVID-research mice," he says, asking if they could be placed in the temperature-controlled passenger cabin along with other pandemic supplies, such as PPE. "We were just told no; we couldn't get most airlines to bite on doing it." In the end, a handful of airlines came to the rescue, but getting the mouse model to where it was needed proved extremely difficult as well as expensive, typically doubling in price compared with pre-pandemic costs.

As flight schedules begin to return to normal, it's still not always easy to transport live mice by air. Many airlines have stopped transporting animals due to pressure from animal rights lobbying, or due to the small profit margins associated with animal transport. "I think animal transport is becoming more of a nuisance for airlines," says Syversen.

The logistics involved in air transporting mice from commercial vendors to customers and between university collaborators are complex. It's especially tricky to ship mice by air between university research labs, which

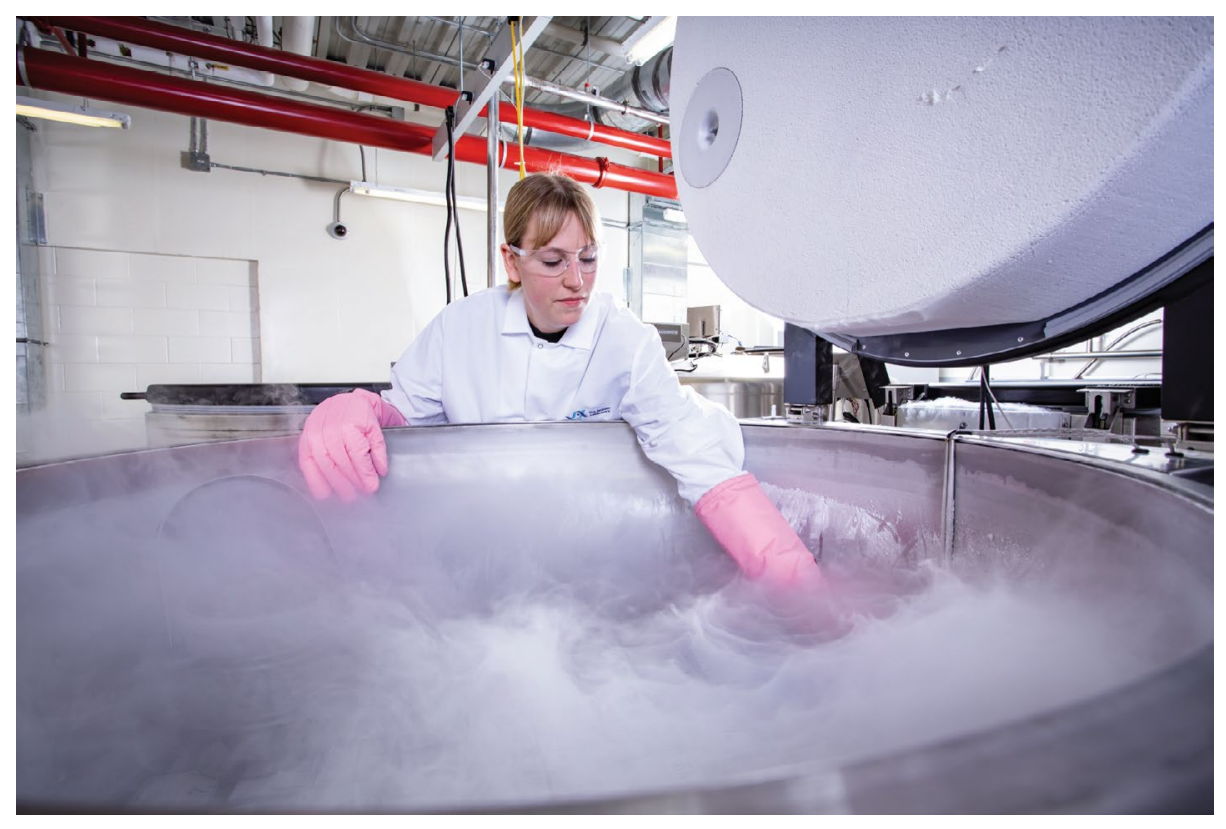

A cool alternative for moving your mice? Credit: The Jackson Laboratory

are often located far from airports and major transport hubs. "There's no cookie-cutter shipments when it comes to the universities," says Syversen. "You're constantly having to get creative - use multiple air carriers and different routings to avoid extreme weather conditions, including summer heat."

The welfare of the mice is extremely important, and their transport must comply with strict requirements. Genetically modified animals are often more vulnerable to environmental challenges, so factors including temperature, humidity and sterility need to be controlled while package damage, handling and stress need to be minimized. "Specialized couriers are essential when shipping live mice," says Renee Araiza, assistant director at the Mutant Mouse Resource \& Research Centers (MMRRC), University of California Davis. "We work with the courier to ensure mice are transported in an environmentally appropriate, controlled, and monitored vehicle."
Of course, road transport is an alternative to flying. Commercial vendors often ship by road where practical, using a hub and spoke system. For example, The Jackson Laboratory (JAX) has dedicated truck routes out of their breeding facilities at Bar Harbor, Maine, and the majority of their live mice are shipped domestically. But road transport is not viable when shipping overseas. To overcome logistical challenges and welfare concerns regarding shipping live mice, many scientists are transporting frozen sperm and embryos.

\section{Life in the freezer}

Cryopreservation uses very low temperatures and cryoprotective agents to preserve structurally intact mouse embryos and sperm. Once at their destination, transported embryos can be transferred to a recipient female and sperm can be used for in vitro fertilization (IVF).

Embryos can be frozen - at the 2- or 8-cell stage - using two main methods ${ }^{1}$, 


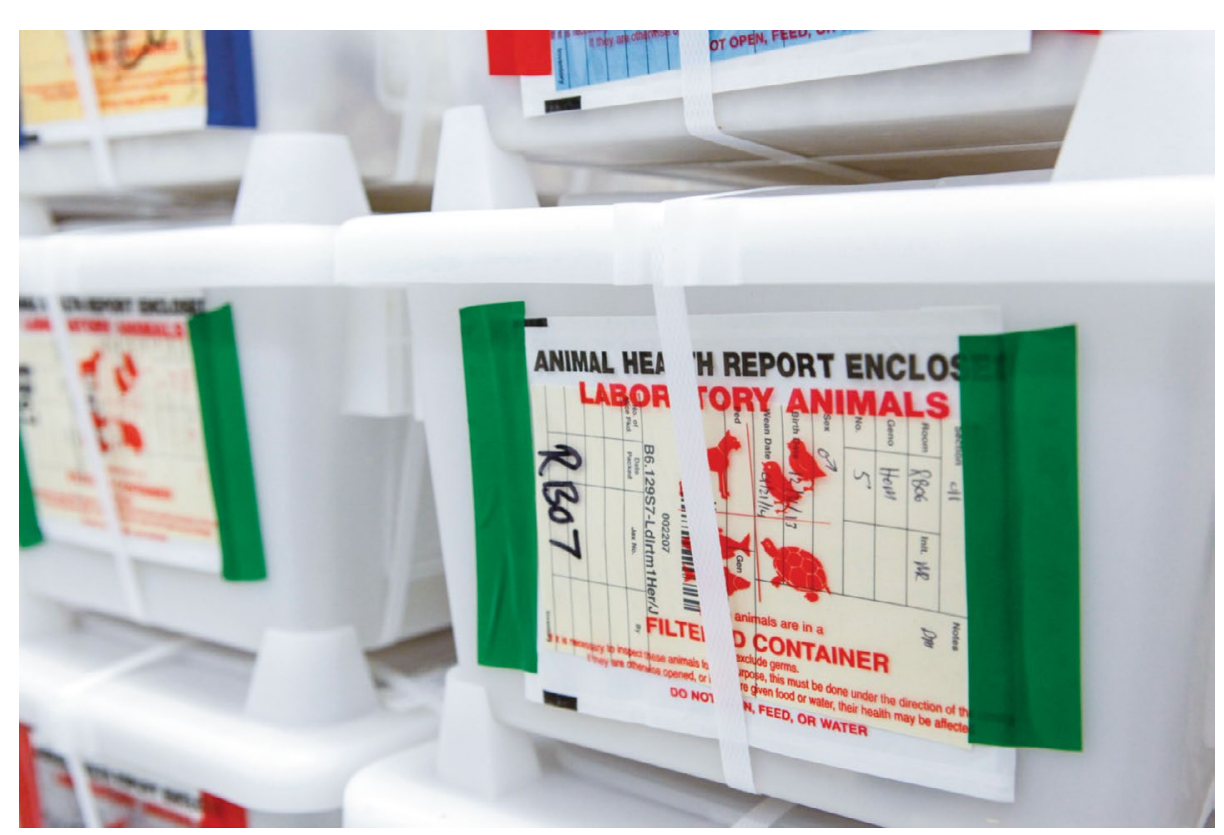

Live mice on the move. Credit: The Jackson Laboratory

each with pros and cons. Controlled-rate freezing slowly lowers the temperature of the embryos, and dehydrates them at the same time to avoid ice forming. But, it requires expensive equipment. The second method, called vitrification, is cheaper. Embryos are frozen very quickly and are rapidly dehydrated using concentrated cryoprotectants. The solution turns to a glass-like state, avoiding the formation of ice crystals. But the method requires a specialized skillset, and the recovery rate of live mice following IVF using vitrified embryos is variable. Nevertheless, "vitrification is picking up in popularity," says Hart-Johnson, head of colony management services at the Francis Crick Institute in London.

Sperm freezing is cheaper, easier and quicker than freezing embryos and just requires access to liquid nitrogen. A turning point in the use of frozen sperm was achieved around 10 years ago when it became possible to recover fertile sperm from C57BL/6 mice - a common strain for generating mouse models ${ }^{2}$. These advances include adding reducing agents, cholesterol-removing agents and glutamine to the cryoprotectant medium.

Cryopreserved material is traditionally transported in so-called dry shippers large aluminum containers containing a spongy material that absorbs liquid nitrogen to enable shipments at about $-190^{\circ} \mathrm{C}$. "We are confident in these when shipping germplasm around the world," says Sarah Hart-Johnson. Dry shippers hold their temperature for as long as 21 days, although many researchers try to limit shipments to 7 days. She notes that Covid-19 caused cargo to be bumped, causing delays.

"The good thing about frozen stock is that if it gets stuck while waiting for another flight it's OK."

Still, the high cost of using dry shippers used to transport cryopreserved germplasm can be an issue. One supplier noted that it costs around US $\$ 3200$ to send a dry shipper from the United States to Australia. The shippers are reusable (they must be sent back to the sender), and germplasm from many mouse strains can be put into a single dry shipper, yet the cost to a small facility can be significant.

To bring shipping costs down, Martin Fray, who runs the cryopreservation facility at the UK's Medical Research Council (MRC) Harwell campus routinely sends out frozen sperm on dry ice ${ }^{3}$, using a regular courier. "It's all kosher and it saves money," says Fray. Frozen sperm can be transported in dry ice $\left(-79^{\circ} \mathrm{C}\right)$ for at least 7 days and returned to liquid nitrogen for long-term storage without detrimental effects. "Money is a big driver and so the lower cost of shipping sperm on dry ice is helping to drive down demand for live mouse shipments," he says.

Of note, Fray says that the European Mouse Mutant Archive, for which MRC Harwell is a node, reached an inflection point in 2017 when the number of frozen shipments exceeded the number of live shipments, and this effect has continued to diverge since then. Indeed, Fray now offers frozen materials as default. If a collaborator requests live mice, they will discuss if this is appropriate - for example, if the mice will only be travelling a short distance. "That's our approach now, we'll direct that discussion and try to avoid shipment of live animals," says Fray.

But there are still a lot of places that don't know how to, or don't have the facilities for cryopreservation. Toru Takeo, Naomi Nakagata and colleagues at the Center for Animal Resources and Development (CARD) at Kumamoto University developed a low-tech technique to send sperm and embryos without needing to cryopreserve them. For sperm their protocol involves dissecting the cauda epididymis - the organ where mature sperm is stored outside the testes - and shipping this in a solution containing cold-protective agents and an organ transplantation medium called Lifor.

This reduces shipping costs compared with cryopreserved samples, and "the yield of embryos by IVF using cold-stored sperm is similar to that of IVF using fresh sperm," says Takeo. The fertility of sperm is maintained for 7-10 days using this technique. Embryos can also be cold-transported. They are chilled at the 2-cell stage and their development is stalled by the cold temperature, giving a window of 4 days to transport them.

The transport of cold rather than frozen germplasm uses simple equipment: a Thermos flask, cold packs and a Styrofoam box. This technique is allowing places without the capacity to freeze to send germplasm. "It doesn't need anything complicated; anyone can work out how to dissect [the cauda epididymis]," says Hart-Johnson. That said, the timing of the arrival of cold shipments is a major consideration for cold-transported germplasm, as it needs to be used almost immediately after arrival. Cold transport can be used to share mouse strains between labs, but is mainly used by researchers to send sperm and embryos to mouse repositories centralized archives of genetically modified mouse strains, which can cryopreserve, store and maintain them for the depositor.

\section{Shipment arrived - what next?}

The choice of whether to ship embryo or sperm "is most of the time dictated by genetics - the number of mutations and the genetic background - of the mouse line," says Jean Cozzi, an innovation manager working with genetically engineered animal models at Charles River. Sperm represents only half the genotype, so additional breeding is required if a homozygous gene model is needed to avoid losing the 


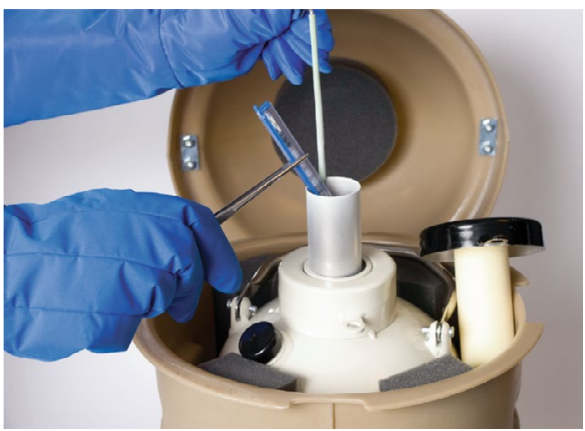

A dry shipper for frozen material. Credit: The Jackson Laboratory

phenotype. Sperm is suitable for mouse lines carrying up to two mutations on a well-defined, homogeneous genetic background. Embryos, which can be used for any mouse line, are the only way to preserve lines harboring several mutations and/or bred on a mixed background. Germplasm sometimes provides extra flexibility for pairing different genotypes of the animal if a researcher wants to backcross a model to a new genetic background.

Regardless of which is chosen, once a shipment of sperm or embryos has arrived at its destination, the receiver then needs to recover the line - that is, get actual mice. Sperm requires access to oocytes and the ability and equipment to do IVF. To improve the user-friendliness of cryorecovering and using sperm (either cold or frozen), several techniques are under investigation. These include improving vitrification of oocytes so that they can be frozen to allow for 'any-time' $\mathrm{IVF}^{4}$, improving the fertility of cryorecovered sperm, for example, using microfluidics-based cell sorting ${ }^{5}$, and establishing better protocols to enable mouse artificial insemination.

Getting an embryo - whether cryorecovered directly or produced via IVF from cryorecovered sperm - into a recipient mouse can only be done by surgically transferring the embryo into the oviduct. The current need for surgery, - and its associated welfare issues, - is a big issue for scientists. The ability to carry out non-surgical embryo transfer (NSET), would, as its name suggests, eliminate the need for surgery. Commercial NSET devices exist, which enable embryos to be transferred to recipient mice using little more than a Gilson pipette. But this device is currently not compatible with early-stage 2-cell embryos that result from IVF. Such embryos cannot be cultured in vitro to a compatible stage ( 8 cells) as "they don't implant efficiently at all," says Fray, who is involved in efforts to improve in-vitro culture using microfluidics technology.

The impact of NSET "would be absolutely massive" says Fray, as it would not only encourage the distribution of 2-cell embryos and sperm, but it could also be used by scientists following gene-editing of embryos. NSET has the big advantage from an animal welfare perspective in removing the need for surgery; "but it's also a lot easier for people to learn, so now you begin to make the technology more accessible and at a lower cost" says Rob Taft, Scientific Director of Reproductive Sciences R\&D at The Jackson Laboratory.

\section{Live or frozen?}

Whether to transport germplasm or live mice "depends very much on where you're at in the world, and what challenges you face in bringing animals into your institution," highlights Taft.

For example, health restrictions imposed by the receiver's institution can play a role; some institutions require quarantine and rederivation of live mice (the transfer of embryos into a pathogen-free recipient). In this case, it is logical to transport frozen germplasm as it is quicker, cheaper and reduces the number of animals used for the rederivation procedure.

If mice are shipped internationally, then national import and export requirements may dictate whether live mice or germplasm is used. Cryopreserved germplasm is often put into a different category from live animals so the requirements - procedures, required documents, pathogen restrictions and so on - can be significantly different. Some countries are very strict about what materials they can import, so importing live mice might be easier if suppliers are not able to comply with specific regulations regarding germplasm.

Away from procedures and regulations, the choice can also depend on the facilities and expertise of the receiver. "We find that some investigators are very adept at recovering live mice from cryopreserved germplasm, while others prefer individual live mice, breeding pairs, or experimental cohorts of male and female mice," says Araiza. Indeed, some people "are really nervous about getting frozen material" says Hart-Johnson, in case the recovery doesn't work. Mice with complex genotypes can be difficult to recover, and so "people do still use live animals a lot," she says.

Convenience can also be a driver for live mice. If an individual researcher can receive live mice at the number needed to run their studies, they avoid the need to co-ordinate with their core facilities to initiate a breeding program - which is a 3-month process following the arrival of frozen germplasm. "And from an animal welfare perspective that's also beneficial as you are not using as many animals to produce the required mice," says Taft.

How frequently a mouse line is to be used also comes into the equation. Advances in gene-editing technologies - such as CRISPR - means there are now thousands of genetically engineered mouse models, many of which are used infrequently but still need to be archived.

Archiving mouse models at a repository is important to ultimately reduce animal use; it prevents researchers re-creating previously developed mouse strains and encourages researchers to share mouse strains. "There are more strains in the cryopreserved stage than kept as live animals," says Leo Chi-Kuang Wang, of the Asian Mouse Mutagenesis Resource Association. So it makes sense for suppliers and model repositories to offer these shipped as germplasm, only recovering them according to the experimental need (some repositories and suppliers can recover a line if a client cannot). But for high-demand lines, such as $\mathrm{C} 57 \mathrm{BL} / 6 \mathrm{~J}$ mice, which are used in large numbers globally, "that is going to be more efficient to supply as live mice," says Taft.

There's still the need to transport live mice - often by air. Syversen is hoping that post-Covid-19, airlines might rethink their no-animal policies, instead viewing the transport of research animals as being for the greater good of "helping medical research." All things considered, whether to transport cryopreserved material versus live mice is a balance that involves weighing up many things: animal welfare issues including the number of mice used, transport stress and the need for surgery, transport options including fight availability and distance, researcher experience and expertise, cost, and even the weather.

\section{Charlotte Harrison ${ }^{凶}$}

Science writer, Canterbury, UK.

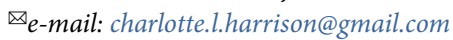

Published online: 9 August 2021 https://doi.org/10.1038/s41684-021-00829-5

References

1. Longenecker, G., Cho, K., Khillan, J. S. \& Kulkarni, A. B. Curr Protoc 1, el38, https://doi.org/10.1002/cpzl.138 (2021)

2. Takeo, T. \& Nakagata, N. Lab Anim 44, 132-137, https://doi.org/ 10.1258/la.2009.009074 (2010).

3. Raspa, M. et al. Theriogenology 96, 49-57, https://doi.org/10.1016/ j.theriogenology.2017.04.003 (2017)

4. Mukunoki, A., Takeo, T. \& Nakagata, N. PLoS One 14, e0224087, https://doi.org/10.1371/journal.pone.0224087 (2019).

5. Nakao, S., Takeo, T., Watanabe, H., Kondoh, G. \& Nakagata, N. Sci Rep 10, 8862, https://doi.org/10.1038/s41598-020-65931-z (2020). 